\title{
Questes
}

\section{Maladie et mort d'un fils : le témoignage de Giovanni di Pagolo Morelli}

\section{Andrea Martignoni}

\section{(2) OpenEdition}

1 Journals

\section{Édition électronique}

URL : http://journals.openedition.org/questes/1778

DOI : 10.4000/questes. 1778

ISSN : 2109-9472

\section{Éditeur}

Les Amis de Questes

\section{Édition imprimée}

Date de publication : 15 mai 2003

Pagination : 10-11

ISSN : 2102-7188

\section{Référence électronique}

Andrea Martignoni, «Maladie et mort d'un fils : le témoignage de Giovanni di Pagolo Morelli », Questes [En ligne], 5 | 2003, mis en ligne le 01 janvier 2014, consulté le 15 septembre 2020. URL : http:// journals.openedition.org/questes/1778

\section{(C) Association des amis de «Questes »}




\section{Maladie et mort d'un fils : le témoignage de Giovanni di Pagolo Morelli

\author{
Andrea MARTIGNONI
}

Ce fut en 1393, à l'âge de 22 ans, que Giovanni Morelli (1371-1444) commença ses mémoires familiales. Dans ses Ricordi, le marchand mémorialiste florentin, retraçant l'histoire de sa famille, vient à évoquer les souffrances qu'endura son fils entre la maladie et la mort. Alberto mourut à l'âge de neuf ans mettant fin aux promesses d'une brillante perpétuation du nom et de l'honneur de la famille Morelli. Son père témoigne alors du difficile travail de deuil. Un deuil qui ne trouvera de répit que dans un abandon complet à la lumière de la miséricorde divine. Des pages émouvantes qui transcendent le temps et qui s'offrent comme un vibrant témoignage, entre rhétorique et sincérité, de la religiosité et de l'éthique du monde marchand florentin à la fin du Moyen Age. Des pages, éditées soigneusement par Vittore Branca, auxquelles, ici, à nouveau il convient de donner voix.

«Le lundi matin du 19 mai 1406 - écrit Giovanni - un malheur survint à mon fils Alberto, qui commença à saigner du nez. Le jour et la nuit suivants, par trois fois le sang lui coula du nez avant même que nous nous aperçûmes qu'il avait de la fièvre [...]. Il vécut de terribles tourments et peines jusqu'au vendredi 5 juin dans la nuit vers trois heures [...]. Il pria bien souvent Dieu et sa Mère, la Vierge Marie, se faisant apporter l'image de la Vierge pour la serrer dans ses bras, prononçant maintes invocations, prières et vœux. Il n'y a pas de cœur si dur et insensible qu'en le voyant ne soit pris par tant d'émotion et de grande pitié [...]. A la fin il mourut; toutes les prières, les vœux et les invocations ne l'aidèrent pas : Dieu voulut que sa vie prenne fin [...]. La perte de ce fils fut une douleur inestimable pour son père et sa mère [...]. Son corps fut inhumé le 5 
juin, un vendredi, à 11 heures, dans Santa Croce, dans le tombeau de famille, dans la partie des hommes, et avec des honneurs funèbres sans faste excessif [...]. Je n'aurais jamais pu penser que cette séparation voulue de Dieu [...] fut pour moi et demeure encore un si cruel coup de poignard. Bien que de nombreux mois se soient déjà passés depuis sa mort, nous ne pouvons, sa mère et moi, l'oublier [...] quelles que soient les conditions où nous nous trouvons il y a un couteau qui nous perce le cœur [...]. Nous sommes partis de la maison pendant un mois et puis, durant tout l'été, on n'occupa plus la chambre ; du jour de sa mort, pendant une période de douze mois, moi, Giovanni, ne rentra plus jamais dans ladite chambre, cela pour aucune autre raison que la grande douleur. $[\ldots]$

Un an s'est déjà écoulé sans que jamais je n'oublie un instant la perte de mon premier et préféré garçon ; mais constamment je fus désespéré et accablé de douleur en me souvenant de lui [...]. Ayant maintes fois prié le miséricordieux fils de Dieu et sa Mère pleine de pitié, la Vierge Marie, pour le salut de l'âme de mon fils [...] je commençais en premier lieu à imaginer et à sonder en moi même tous les péchés par lesquels j'avais offensé le fils de Dieu. Et en prenant conscience combien fut dure, âpre et obscure la passion de Jésus Christ sur le crucifix, dont j'observais la figure, et que, par elle, il avait racheté l'humanité, je ne souffrais guère en l'observant, mais je crois que, par sa propre grâce, mon cœur et mes sens furent envahis par une énorme tendresse, mon visage se mouillant des larmes qui sortaient de mes yeux. " [Voir Mercanti scrittori. Ricordi nella Firenze tra Medioevo e Rinascimento, sous la direction de V. BRANCA, Milano, Rusconi, 1986 ; mais aussi Giovanni di Pagolo Morelli, Ricordi, éd. de V. BRANCA, Firenze, Le Monnier, 1969 (1959)]. 